\title{
The black thyroid: an unusual finding during neck exploration
}

\author{
J.G. Noble, T.J. Christmas, C. Chapple, D. Katz' and E.J.G. Milroy
}

Departments of Urology and ${ }^{1}$ Histopathology, The Middlesex Hospital, Mortimer Street, London WIN 8AA, UK.

\begin{abstract}
Summary: Black thyroid discolouration has been reported in post-mortem examinations on patients who have previously taken minocycline. The discovery of this phenomenon during neck exploration and a review of the possible mechanism of black thyroid discolouration are discussed in this paper.
\end{abstract}

\section{Introduction}

The chance finding of coal-black thyroid discolouration during neck exploration is an unusual and bewildering event for the surgeon. A review of the world literature reveals that black pigmentation of the thyroid gland is rare, poorly recognized and is usually associated with chronic minocycline therapy. ${ }^{1}$ We report finding a case of a black thyroid diagnosed peroperatively and review the possible pathogenic mechanism of this disorder.

\section{Case report}

A 21 year old man presented with a history of frank haematuria and was found to have renal calculi. A metabolic screen revealed an elevated serum calcium level $(2.95 \mathrm{mmol} / \mathrm{l})$ and parathyroid hormone level $(0.45 \mathrm{ng} / \mathrm{l})$. His thyroid function tests were within normal limits. A diagnosis of primary hyperparathyroidism was made and he underwent neck exploration.

At operation the thyroid gland was found to be uniformly coal-black in colour but was otherwise macroscopically normal. A section of thyroid gland was excised because of its grossly abnormal appearance (Figure 1). A parathyroid adenoma, which was not made any easier to identify by the thyroid pigmentation, was excised.

Post-operatively, questioning revealed that the patient had received a course of minocycline $100 \mathrm{mg}$

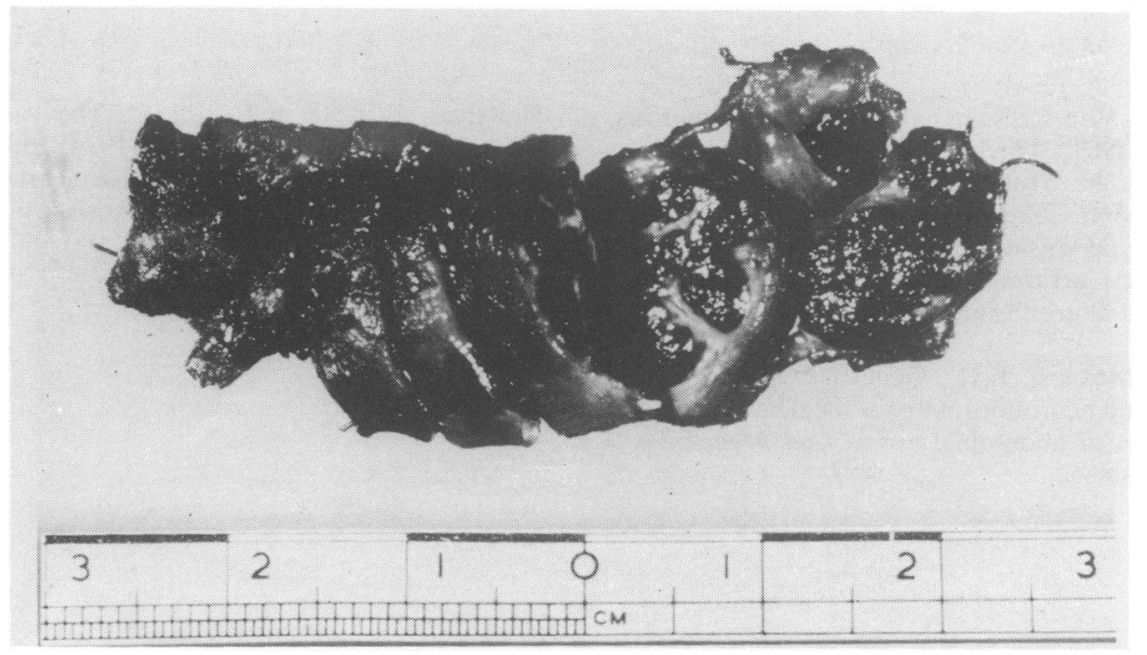

Figure 1 Cut surface of thyroid gland showing uniform black discolouration.

Correspondence: J.G. Noble, M.B., B.S., Department of Urology, The Westminster Hospital, Dean Ryle Street, Horseferry Road, London SW1P 2AP, UK.

Accepted: 10 August 1988 


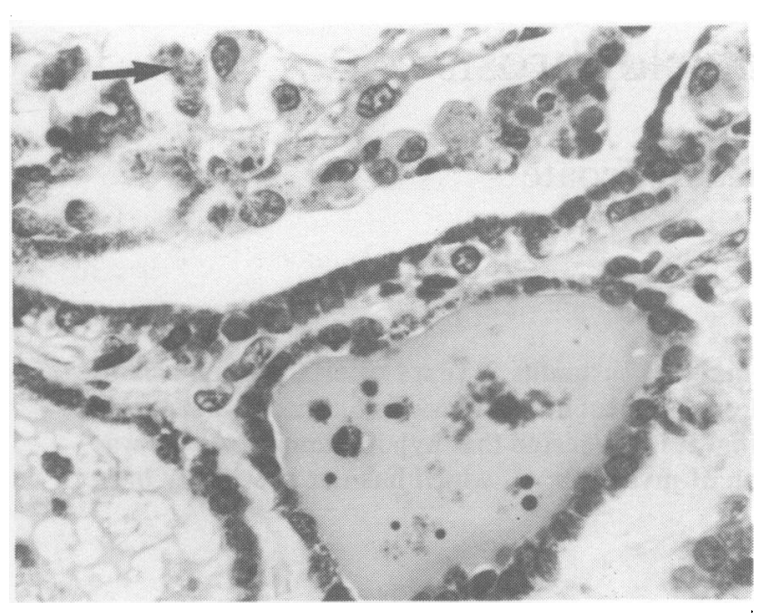

Figure 2 Histological view of black thyroid gland demonstrating intracellular deposition of pigment granules.

twice daily over a period of 3 months for the treatment of acne. Histological examination of the excised thyroid tissue demonstrated normal follicular pattern with multiple fine dark brown granules within the cells lining follicles (Figure 2).

\section{References}

1. Landas, S.K., Schelper, R.L., Tio, F.O., Turner, J.W., Moore, K.C. \& Bennett-Gray, J. Black thyroid syndrome: exaggeration of a normal process? Am J Clin Pathol 1986, 85: $411-418$.

2. Basler, R.S.W. Minocycline therapy for acne. Arch Dermatol 1979, 115: 1391.

3. White, S.W. \& Besanceney, C. Systemic pigmentation from tetracycline and minocycline therapy. Arch Dermatol 1983, 119: 1-2.

4. Benitz, K.F., Roberts, G.K.S. \& Yusa, A. Morphological effects of minocycline in laboratory animals. Toxicol Appl Pharmacol 1967, 11: 150-170.

\section{Discussion}

Minocycline is a broad spectrum, bacteriostatic, semisynthetic tetracycline derivative and is indicated for the treatment of a variety of Gram-positive and Gram-negative infections. Pigmentation of the skin, ${ }^{2}$ bone, ${ }^{3}$ substantia nigra and atherosclerotic plaques ${ }^{1}$ has also been associated with minocycline therapy.

In animal trials conducted before the introduction of minocycline in 1972 marked black discolouration of the thyroid gland was observed without any adverse effect on thyroid function. ${ }^{4}$ Since that time only 12 presented reports have appeared in the literature detailing this problem in man.

The pigment identified in previous cases of black thyroid glands has been evaluated as neuromelanin, lipofuscin or a minocycline oxidation product. ${ }^{5,6}$ Although lipofuscin and neuromelanin production occurs in the normal thyroid gland with advancing age it would appear that minocycline may accelerate this pigment accumulation either by increasing the number of products of oxidation in the thyroid epithelium ${ }^{4}$ or by stimulating melanosis of the thyroid gland by acting as an additional premelanin substrate. ${ }^{7}$

This case demonstrates an extremely rare but nonetheless striking operative finding which is immediately recognized and can be predicted if a previous history of minocycline therapy is obtained prior to surgery.

5. Medeiros, L.J., Federman, M., Silverman, M.L. \& Balogh, K. Black thyroid associated with minocycline therapy. Arch Pathol Lab Med 1984, 108: 268-269.

6. Reid, J.D. The black thyroid associated with minocycline therapy: a local manifestation of a drug-induced lysosome/substrate disorder. Am J Clin Pathol 1983, 79: $738-746$.

7. Kelly, R.G. \& Kanegis, L.A. Metabolism and tissue distribution of radioisotopically labelled minocycline. Toxicol Appl Pharmacol 1967, 11: 171-183. 